MOTOR DEVELOPMENT IN INFANTS WITH ESOPHAGEAL ATRESIA: THE CRITICAL IMPORTANCE OF ORAL FEEDING EXPERIENCE. Scot Dowling and Donna DeMonterice (intr. by Marshall Klaus), Case Western Reserve Univ. Depts. of Ped, and Ped. Nursing, Cleveland.

To study the effects of altered oral experience on development, five children with unrepaired esophageal atresia were observed from birth for periods of 8 months to 9 years. Three children were fed only by gastrostomy while two had a full range of oral experiences including sham oral feedings of milk and baby foods (which drained through a cervical esophagostomy), given simultaneously with gastrostomy feedings so as to retain the oral reflexes and cyclic hunger and satiation. The influence of maternal deprivation on the infants' development was anticipared, evaluated, and minimized by supportive assistance to the family. Direct observations of the mothers and infants were supplemented by films, developmental testing and the parents' written observations.

The 3 infants in whom oral experience was severely deficient from birth had marked gross motor retardation without neurological or mental deficits. In addition they rarely showed intense responses, such as anger, had little attachment to toys and had nonspecific responses to their parents' presence or absence. Despite adequate caloric intake these 3 children were all below the third percentile in weight and body length after the sixth month. In sharp contrast, the 2 children who had a full range of oral experience were normal in every respect. The results suggest that early oral feeding experiences may profoundly influence motor development.

\section{IMPROVING PATIENT CARE}

Daniel S. Fleisher and Charles omdal. Temple Univ. Sch. of Med.

St. Christopher's Hosp. for Chilaren Philadelphia

The "Bicycle Process" is a systematic approach that requires health care providers to establish their own minimal standards of patient care. Any performance below their minimally accepted level is called a performance deficit. Educational programs are instituted for each performance deficit after which their performance is remeasured. To be successful the process requires at least the cooperation of physicians, administrators, boards of trustees and medical record analysts.

At one children's hospital attempting to institute the "Bicycle Process", the staff created 54 standards of care for 3 comonly encountered conditions (meningitis, asthma and pneumonitis). Performance deficits were shown for 34 standards before and 29 standards after the educational programs. of the 29 remaining deficits, 20 showed improvement, 6 worsened and 3 remained unchanged.

Thus, the "Bicycle Process" can lead to significant improvements in patient care and warrants close inspection by all who render patient care.
EFFECT OF EDUCATION ON THE ATHEROSCLEROTIC RISK FACTORS OF CHILDREN AND THEIR PARENTS.

Stanley J. Goldberg, Hugh D. Allen, Glenn Frledman, John A. Gaines. Univ, of Arizona, Col, of Med., Univ. Hosp., Dept. of Ped., Tucson.

isk factors (R,F.) of atherosclerosis include hypercholesterolemia, hypertension, obesity, lack of physical exercise and smoking. R.F. screening in children is now common, but intervention is rare. This study evaluated the change between results of two control screening sessions and two post education screenings three and six months later. Education was limited to seven hours of group lectures. Subjects were 199 entire families of $11 \mathrm{fe}$ underwriters. Participants' ages ranged from one to 70 years, with a large concentration of children ( $48 \%$ of 715 subjects). The following data were found. Weight increased slightly in young children but fell significantly in older children and adults. Skin fold thickness decreased significantly in all male groups, and increased significantly in all female groups early but later fell significantly. Systolic and diastolic blood pressure fell significantly in all groups with a mean decrease of 5.5 and $4.3 \mathrm{~mm} \mathrm{Hg}$ respectively. Serum cholesterol decreased significantly in all age groups with the maximum mean decrease occurring in the teenage female group (26mgm\%) and young adult male group $(21 \mathrm{mgm} \%)$. Cholesterol continued to decrease with time. Participants decreased smoking and increased exercise. Results indicate that minor educational efforts can produce significant long term improvement of R.F. In families.
A COMPARISON OF PEDIATRIC INTERVIEWING SKILLS USING REAL AND STMULATED MOTHERS Ray E. Helfer, Mary A. Black, Howard me William B. Weil, Jr.) Col. of Human Med. Michigan State University, Dept. of Human Development.

In order to allay concerns about using simulators as opposed to real mothers for teaching and evaluating interviewing skill, a study was designed to test for differences in students' approaches when interviewing simulated and real mothers. Three mothers were trained to give their own child's history consistently and two mothers trained to simulate a history. $30 \mathrm{Yr}$. III medical students conducted 2 interviews which were audiotaped. Students were told the nature of the study and whether the "mother" was real or simulated. Half of the time the mothers were presented as simulators and half of the time the simulators were presented as mothers. The variable of order was controlled.

An objective checklist containing $70-80$ bits of organic and personal data per case as well as a modified interaction analysis (with an average of 285 interactions per interview) were utilized to measure the content material and approach used by the students. The data were analysized using an Analysis of Variance (ANOVA) technique. All hypotheses were accepted, i.e., no significant differences were found in any of the groupings examined. (truth, lie, simulator, mother) for any of the variables.

THF USE OF SIMULATION FOR TEACHING AND EVALUATING INTERVIEWING SKILLS PROVIDES A VALID FXPERIENCE.

EXPERIENCES OF CHILDREN AND PARENTS IN A HEMODIALYSIS AND KIDNEY TRANSPLANT PROGRAM. Richard Holdredge, Richard N Fine, and Barbara M. Korsch, Div, for Research and Training in Rehab., USC School of Med., 1739 Griffin Ave., Los Angeles, and Childrens Hospital of Los Angeles, Los Angeles, Calif.

The presentation consists of a video transfer documentary dealing with the emotional and social aspects of hemodialysis and kidney transplantation. The experiences and perceptions of children and families in the program as well as those of the medical care team are documented on film with narration composed of segments of interviews with patients, parents, staff conferences, etc. Interactions within the dialysis unit and in the operating room as well as encounters with patients in the clinics, on the wards and in patients' homes are included.

The film emphasizes the need for planning treatment in light of the patient's personality, developmental stage and family background in an awareness of the patient's value system, which is not always congruent with that of the medical establishment. 